\title{
AVALIAÇÃO DO ENSINO - APRENDIZAGEM NA PERCEPÇÃO DE DISCENTES E DOCENTES NO CURSO DE LETRAS DA UNIVERSIDADE ESTADUAL VALE DO ACARAÚ (UVA)
}

\author{
EVALUACIÓN DE LA ENSEÑANZA-APRENDIZAJE EN LA PERCEPCIÓN DE \\ DISCENTES Y DOCENTES EN EL CURSO DE LETRAS DE LA UNIVERSIDADE \\ ESTADUAL VALE DO ACARAÚ (UVA)
}

\author{
EVALUATION OF TEACHING-LEARNING FROM THE PERSPECTIVE OF \\ TEACHERS AND STUDENTS OF DEGREE IN LANGUAGES (PORTUGUESE) \\ AT UNIVERSIDADE ESTADUAL VALE DO ACARAÚ (UVA)
}

\author{
Neudiane Moreira FELIX ${ }^{1}$ \\ Evaneide Dourado MARTINS ${ }^{2}$
}

RESUMO: O presente artigo é resultado de uma pesquisa realizada no Curso de Letras, na Universidade Estadual Vale do Acaraú (UVA), em Sobral, Ceará. O objetivo foi compreender a percepção de discentes e docentes sobre a avaliação do ensinoaprendizagem. No referencial teórico abordamos autores como: Antunes (2001), Carneiro (1998), Freire (1983, 1996), Hoffman (2011), dentre outros, que pesquisam sobre a avaliação e as suas influências no processo de ensino e aprendizagem. Ressaltamos ainda a consulta realizada nos documentos institucionais do Curso de Letras para obtenção de informações a respeito do processo formativo dos que cursam tal graduação na UVA. A pesquisa foi de natureza qualitativa, configurando-se como estudo de caso e os procedimentos metodológicos compreenderam nos relatos dos docentes e discentes do referido Curso, a partir do questionamento aberto: "O que você entende por avaliação?" Os resultados obtidos nos permitiram perceber uma vertente transformadora das práticas dos docentes e sua preocupação com a superação do binômio teoria-prática, através de atividades que envolvam os espaços sociais e pedagógicos de atuação do licenciado. Podemos perceber também que há uma necessidade muito intensa de se proceder a problematização dialogal das vivências e aprendizagens da sala de aula realizando-se rotineiramente múltiplas reflexões que possam revelar as crenças educativas que permeiam o imaginário e as relações existentes entre os protagonistas da práxis educacional: educadores e educandos, em face da avaliação.

PALAVRAS-CHAVE: Avaliação do ensino-aprendizagem. Docentes. Discentes.

\footnotetext{
${ }^{1}$ Instituto Superior de Teologia Aplicada (INTA). Departamento de Educação a Distância do INTA. Professora Pesquisadora II do Plano Nacional de Articulação e Formação de Professor da Educação Básica - PARFOR/UVA/CAPES. E-mail: cesecgeral.neudiane@ hotmail.com

${ }^{2}$ Instituto Superior de Teologia Aplicada (INTA). Professora dos cursos na Modalidade a Distância pelo Centro Universitário INTA. Roteirista multimídia de material didático da Pró-Diretoria Pedagógica de Novas Tecnologias em Educação e Educação a Distância do INTA. E-mail: neidedouradomartins@ @otmail.com
} 
RESUMEN: Este artículo es el resultado de una encuesta realizada en Curso de Letras en la Universidade Estadual Vale do Acaraú (UVA) en Sobral, Ceará. El objetivo fue comprender la percepción de estudiantes y profesores en la evaluación de la enseñanza y el aprendizaje. En enfoque de los teórico como: Antunes (2001), Carneiro (1998), Freire (1983, 1996), Hoffman (2011), entre otros, en la investigación sobre la evaluación y sus influencias en el proceso de enseñanza y aprendizaje. Itaciendo hincapié en la consulta en los documentos institucionales del Curso de Literatura para obtener información sobre el proceso de in formaciòn que asisten a la graduación en la UVA. La investigación fue de naturaleza cualitativa, mediante la creación de un estudio de curso y los procedimientos metodológicos incluidos en los informes de los profesores y estudiantes de ese curso, a partir de la pregunta abierta: "¿Qué quiere decir por crítica?" Los resultados nos permitieron hacer realidad un aspecto de transformación de las prácticas de los docentes y su preocupación con la superación de la teoría y la práctica del binomio a través de actividades relacionadas con los espacios sociales y de estudios Licenciatura actuar. También nos damos cuenta de que hay una intensa necesidad de llevar el interrogatorio del dialógico de experiencias y aprendizaje en el aula, la realización rutinaria de múltiples reflexiones que pueden revelar las creencias educativas que impregnan el imaginario y la relación entre los protagonistas de la praxis educativas : profesores y estudiantes, en la cara de la evaluación.

PALAVRAS-CLAVE: Evaluación de la enseñanza-aprendizaje. Docentes. Discentes

ABSTRACT: This paper is a result form a research applied to Degree in Languages (Portuguese) course at Universidade Estadual Vale do Acaraú (UVA), located in Sobral, estate of Ceará, Brazil. The aim was to comprehend the perspective from professors and students about the evaluation of the teaching-learning process. In theoretical reference we refer to authors like: Antunes (2001), Carneiro (1998), Freire (1983, 1996), Hoffman (2011), and others who research about evaluation and its influences on teaching and learning processes. We emphasize the consultation accomplished on institutional documents of Degree in Languages (Portuguese) in order to gather information regarding the formative process of those who attend to that degree at UVA. The research had a qualitative nature, being configured as a case study and the methodological procedures included both professors and students testimonials, from the subjective question: "What do you understand by evaluation?". The results allowed us to perceive a transforming aspect of professors' practices and their concern with overcoming the theory and practice binome, through activities that involve graduates' social and pedagogical areas of work. We can also perceive that there is a very intense need to proceed with a dialogical problematization of classroom experiences and learning, working everyday with multiple reflections that can reveal the educational beliefs that permeate the imaginary and the existing relationships between the protagonists of the educational praxis: educators and learners, in face of the evaluation.

KEYWORDS: Teaching-learning evaluation. Professors. Students. 


\section{Introdução}

Este estudo surgiu de nossas inquietações sobre a avaliação nas salas de aulas, pela experiência no ensino na educação básica e pelas aprendizagens na educação superior, sobretudo, no Curso de Letras da UVA, que tem a responsabilidade de formar os profissionais para docência em Língua Portuguesa e em Língua Inglesa.

Nunca foi tão necessário romper paradigmas arcaicos e tornar a prática avaliativa mais prazerosa para educadores e educandos, uma vez que a ação educativa vem sofrendo uma constante invasão tecnológica e o docente já não é mais o único detentor do conhecimento na sociedade em que vivemos.

Assim, nosso estudo pretende investigar como os discentes e docentes, percebem a avaliação do ensino-aprendizagem, no Curso de Letras da Universidade Estadual Vale do Acaraú (UVA), enquanto instância formadora de novos profissionais de educação, sendo a mesma convocada a promover uma intensa revisão do significado das exigências burocráticas da avaliação e a sua reestruturação, para além de uma concepção meramente sentenciva ou de julgamento de resultados prontos e acabados das aprendizagens dos educandos.

"O tema de avaliação é bastante complexo, O que, como e para que avaliar, são questões que tomamos ao pensar no tema" (MAGALHÃES; MASIGLIA, 2013 p. 235).

Quando pensamos em avaliação ou nos procedimentos avaliativos, alguns questionamentos básicos acabam aflorando tais como: a) Para que serve a avaliação? b) Por que estamos avaliando? c) Quem será beneficiado/prejudicado com o resultado obtido na avaliação? d) Como podemos romper com estruturas arcaicas da avaliação e conduzir nossos discentes a novos patamares de compreensão do ato avaliativo e de mudança cultural da sociedade? e) Sabemos verdadeiramente avaliar? f) Estamos ainda tão somente testando e medindo na Universidade como outrora fomos avaliados em nossos processos formativos?

Não podemos negar que as exigências burocráticas das Instituições de Ensino Superior - IES em reduzir as observações, atividades, projetos, ações em notas, conceitos ou pareceres finais causam confusões de terminologias e de procedimentos avaliativos nos Cursos de Graduação do nosso país. Algo que já é muito comum nas escolas de educação básica, onde os educadores são meros reprodutores de seus processos avaliativos anteriores. 


\section{Avaliação em seu contexto histórico}

Quando falamos em avaliação no Brasil não podemos deixar de lembrar a influência dos Jesuítas que chegaram ao Brasil e trouxeram com eles o pensamento clássico de educação. A pedagogia dos Jesuítas era baseada na ótica teocêntrica da escola tradicional que direcionava seus ensinamentos para a religião. O ensino de caráter dogmático compreendia o homem como um ser descaracterizado de qualquer saber e que precisava ser preenchido com o conhecimento verdadeiro repassado inquestionavelmente pelo professor, que era o detentor do saber puro.

No Brasil esse modelo de educação exerceu forte influência no cenário educativo brasileiro. A avaliação também se fixou na prática desses professores. $\mathrm{O}$ modelo avaliativo baseado na "cultura" da prova, da premiação, da punição e dos deveres de casa e teve sua raiz na prática de educadores religiosos.

O professor é posto como um juiz que irá julgar o que o aluno aprendeu, o que adquiriu de conhecimentos e em troca são oferecidos títulos de honra, diplomas, medalhas, anéis, prêmios, entre outros, e por outro lado, castigo e reprovação para aqueles que não conseguiram aprender os conteúdos repassados.

No ensino de cunho tradicional que predomina ainda hoje nas escolas brasileiras, se percebe claramente a necessidade de consolidação do poder burguês. No primeiro momento do ensino tradicional a escola surge como um antídoto à ignorância, um instrumento para resolver o problema da marginalidade. Ela se organiza como uma agência centrada no professor, que transmite gradativamente o acervo cultural aos alunos. A este cabe assimilar os conhecimentos que lhes são transmitidos.

Metodologicamente as escolas eram organizadas em classes, cada uma com professor que expunha as lições, que os alunos deveriam ouvir e fazer os exercícios referentes. Daí o ensino corresponde a uma aprendizagem onde o professor oferece a matéria e uma lição para o aluno fazer, no qual na próxima aula faz uma recapitulação da aula anterior corrigindo os exercícios; se todos fizerem passa a frente, se ficaram dúvidas é preciso que se prolongue mais um pouco nesta matéria, depois de solucionar todos os problemas, pode prosseguir com a matéria.

Em se tratando da proposta da Pedagogia Tradicional o modelo pedagógico descrito acima é o mais usual, no entanto, convém que salientemos que quando o aluno não consegue aprender acaba tendo de abandonar a escola, pois o professor só transmite a matéria e não se preocupa em ajudar os alunos no ato de solucionar suas dúvidas. 
O formalismo e a memorização são uma das bases dessa prática pedagógica. Uma vez que a Pedagogia Tradicional acredita que o aluno deve seguir um modelo, a memorização é o melhor caminho para fazê-lo. Sobre isto, Garcia (2008, p. 35) destaca que:

[...] o prazer de aprender desaparece quando a aprendizagem é reduzida a provas e notas, os alunos passam a estudar 'para se dar bem na prova' e para isso tem de memorizar as respostas consideradas certas pelo professor ou professora. Desaparecem o debate, a polêmica, as diferentes leituras do mesmo texto, o exercício da dúvida e do pensamento divergente, a pluralidade. A sala de aula torna um pobre espaço de repetição, sem possibilidade de criação e circulação de novas ideias.

Para garantir que o aluno memorizou, o mestre toma a lição do aluno, que deve responder repetindo com exatidão o que foi dito em sala de aula. $\mathrm{O}$ esforço para esse paradigma é necessário à educação. Para estimulá-lo, os alunos que conseguem seguir modelos, recebem prêmios (medalhas, distinções, quadro de honra) e os que não conseguem devem ser castigados.

Neste contexto, Libâneo (1994) nos alerta que ao aluno não é ensinado a cooperar, mas a competir. As atividades são feitas individualmente (a maioria delas são meramente simples reproduções do conteúdo repassado), e não em grupo.

$\mathrm{O}$ autor assevera que o respeito à autoridade nos diz como a Pedagogia Tradicional vê a atuação do professor. Ele é um depositário de conhecimentos, uma autoridade, um modelo, que reflete os modelos do passado glorioso da humanidade (os grandes filósofos, os grandes cientistas, os modelos tidos como universais).

Segundo Freire (1996), a escola é organizada de forma em que o aluno encontrase sujeito à autoridade do professor e este sujeito à autoridade do inspetor e este sujeito à autoridade do diretor, em graus hierárquicos sucessivos e típicos do sistema escolar.

A principal metodologia de ensino utilizada é a aula expositiva e a demonstração do professor à classe, tomada como auditório passivo e obediente ao seu discurso ou monólogo. Ao aluno cabia apenas receber passivamente as informações transmitidas pelo professor e repeti-las corretamente.

Freire (1983) chamou essa pedagogia de educação bancária, pois o professor 'depositava' os conteúdos na cabeça dos alunos. Nesta pedagogia a avaliação passou a ser vista como uma forma de verificar se o aluno reteve o conhecimento repassado pelo professor, e não uma oportunidade de compreender o conhecimento adquirido. Batista e Ibiapina, (2016, p. 1997) declaram que: 
Dessa forma, a prática avaliativa tradicional, caracteriza-se como modalidade de caráter classificatório utilizada como instrumento de poder pelos docentes para medir a capacidade dos alunos em reproduzir os conteúdos transmitidos em aula, tornando-se um meio de controle do nível cognitivo, medido pela nota obtida nos testes.

Vale destacar que se o aluno não conseguisse decorar o que o professor passou, era punido com uma nota baixa (antigamente, em alguns casos extremados a punição incluía castigos físicos como o uso da palmatória e a permanência em salas escuras, no mais elevado isolado dos demais membros da sala de aula).

É importante percebermos que na sua versão mais difundida, a avaliação ainda é feita pontualmente, através de provas objetivas. Neste cenário, ocorre que em um único momento, o aluno é testado e seu desempenho no processo de aprendizagem tem pouca importância na avaliação.

Para Libâneo (1994), a sala de aula é vista como local privilegiado de aprendizado e as experiências exteriores a ela são pouco valorizadas, porque as relações sociais não são aceitas no campo educacional por serem portadores dos conflitos e das desigualdades existentes no seio da sociedade.

Segundo Freire (1996), a Pedagogia Tradicional ainda está presente em quase todas as salas de escolas brasileiras, com maior ou menor intensidade nas práticas docentes, embora se conceba que ela venha sendo criticada há mais de um século.

Percebe-se que a maioria das escolas e das faculdades brasileiras, apesar do seu discurso inovador e das suas modernas filosofias de trabalho pedagógico, ainda privilegia a Pedagogia Tradicional. Isto se deve principalmente ao fato incontestável que os docentes são estimulados a repassarem avaliações tradicionais, repetitivas, de pura memorização dos conteúdos programáticos apresentados em sala de aula, o que acaba facilitando a permanência do processo burocrático interno das instituições de ensino.

Além desse forte argumento didático, a maioria das instituições ainda percebe a sala de aula como único local possível de aprendizagem, esquecendo-se que na atualidade os discentes são lançados em modernas tecnologias de aquisição do conhecimento. Nesse sentido, ainda percebemos nas escolas e faculdades a exigência exacerbada de cumprimentos de horários na sala, em detrimento das possibilidades exteriores do ambiente escolar, tais como: pesquisas, passeios e participação em eventos culturais. 
Quando os docentes brasileiros começaram a questionar o enfoque dogmático da Pedagogia Tradicional e a necessidade de melhor conduzir o processo de aprendizagem foram surgindo outras pedagogias brasileiras. Nesse sentido, a solução mais evidente do problema pedagógico não está em transmitir o saber sistematizado, que é uma atividade voltada para o passado, mas em preparar os jovens de hoje para um futuro aberto no qual haver muito mais novidade do que jamais sonhamos ou até mesmo idealizamos.

\title{
Conceptualizações sobre avaliação
}

A avaliação tem sido uma temática recorrente nas pesquisas educacionais e ainda se encontra em uma teia de profundas reflexões e impasses. Muitos tentam associar o ato avaliativo ao mero uso de determinados instrumentos avaliativos, sem inserir outros elementos que podem tornar o ato avaliativo mais compreensivo e produtivo para educadores e educandos.

Não são poucas as definições que encontramos quanto ao entendimento e ideia de avaliação, isto porque a avaliação não se resume apenas num processo a realização de provas e atribuição de notas. A avaliação é muito mais do que um registro de perguntas e respostas, a serem respondidas por estudantes em épocas de provas. De acordo com Magalhães e Masiglia (2013 p. 245):

\begin{abstract}
A avaliação é a verificação da aprendizagem a partir dos componentes anteriores. É claro que a constatação do que o aluno aprendeu não se dá por meio de um único instrumento, mas devemos planejar situações nas quais possamos avaliar o que o aluno está aprendendo e assim replanejar as ações, seja para potencializar ainda mais o que estamos ensinando, seja para buscar outras estratégias mais adequadas às proposições do ensino.
\end{abstract}

A avaliação é um componente do ensino que possibilita ao aluno mostrar seu desempenho e as competências adquiridas como resultados de sua aprendizagem. Serve também para o docente verificar sua prática e melhorar suas estratégias metodológicas em sala de aula. É assim um elemento de mão dupla na educação. Sua influência pode ser percebida entre os professores e os estudantes, com enfoques mais intensos nos resultados da aprendizagem.

Para melhor compreender a assertiva acima, vale ressaltar a definição de Saviani (1967, p. 195), ao afirmar que: 
[...] A avaliação é uma tarefa didática necessária e permanente do trabalho docente, que deve acompanhar passo a passo o processo de ensino e aprendizagem. Através dela os resultados que vão sendo obtidos no decorrer do trabalho conjunto do professor e dos estudantes que são comparados com objetos propostos a fim de constatar progressos, dificuldades e reorientar o trabalho para as correções necessárias.

O processo avaliativo é de fato uma tarefa complexa. Está claro pelas afirmações acima que a função da prática avaliativa não é simplesmente atribuir valores ou conceituar notas. A nota por si mesma não caracteriza nenhum tipo de aprendizagem, é comum encontrarmos educadores que ainda não observaram o real conceito e objetivo da avaliação, transparecendo para seus educandos uma sensação ruim quando o assunto é "prova", que para alguns é a arma que o professor se utiliza para sentenciar o aluno.

Estes procedimentos estão bem distantes da real função avaliativa que tem por base submeter o educando a expor suas competências adquiridas e ajudá-lo a adquirilas, caso essa aprendizagem não tenha sido atingida de forma satisfatória.

A avaliação é indispensável e tem fortes condicionantes nas relações que serão construídas entre educadores e educandos, definindo oportunidades de maiores motivações entre ambos no binômio ensino-aprendizagem. Sobre isto, Hoffmann (2011 p. 83) afirma que:

A relação professor-aluno também ficou mais gostosa, pois só agora entendo que o educador não é o dono do saber, ou seja, aquele que despeja ou apenas repassa todo o seu conhecimento sobre os estudantes, mas sim aquele que orienta, incentiva, redescobre e muitas vezes até aprende com os estudantes.

Conforme os estudos sobre o processo de avaliação, o que temos constatado é que avaliação não tem se caracterizado numa forma educacional que possibilite o crescimento e a aprendizagem necessária do aluno. Pelo contrário, muitas vezes é tão somente percebida como disciplinadora, punitiva e discriminatória. (HOFFMANN, 2011).

Para que a avaliação suscite resultados satisfatórios à aprendizagem, o essencial é conhecer que tipo de discente se está avaliando e quais são suas verdadeiras necessidades. A avaliação só faz sentido se tiver o intuito de buscar caminhos para melhorar a aprendizagem. Tendo em vista essa perspectiva, o professor poderá pensar em múltiplos caminhos para que todos alcancem os objetivos desejados. Segundo Barreto et.al., (2017, p. 1008), “a avaliação é o processo central de um ensino eficaz e, é 
por meio dela que podemos descobrir se o planejamento de atividades propostas de ensino resultou em aprendizagem”. Conforme Perrenoud (1999), todas as intervenções do professor favorecem supostamente as aprendizagens, mesmo indiretamente, criando e mantendo condições propícias ao trabalho intelectual e a comunicação pedagógica.

\section{Percurso metodológico}

Para esta investigação, além das pesquisas bibliográficas que subsidiaram a compreensão teórica da temática proposta, foi realizada uma pesquisa de campo, envolvendo docentes e discentes da UVA. A luz do referido suporte teórico adotou-se um formulário padronizado para coleta de depoimentos/ relatos dos docentes e discentes do Curso de Letras, a partir do questionamento básico: O que você entende por avaliação? E a partir deste encaminhamento, o depoente ramificava sua resposta sobre como gostaria de ser avaliado, que tipo de instrumento avaliativo seria produtivo e que sugestões gostaria de oferecer sobre esta temática para melhoria do referido Curso.

Para uma melhor compreensão do que propomos investigar além dos autores já mencionados, apoiamo-nos também nos Parâmetros Curriculares Nacionais (PCNs, 1998), por apresentarem um repertório bastante significativo de orientações sobre as abordagens avaliativas na educação básica, que podem auxiliar as posturas dos educadores nas salas de aulas do país, inclusive na educação superior.

O objetivo do depoimento era direcionado a perceber nos relatos coletados uma possível análise das atitudes e dos sentidos psicológicos e pedagógicos sobre a avaliação, enquanto processo formativo e sua interface com a melhoria da qualidade do ensino e da aprendizagem.

$\mathrm{Na}$ presente pesquisa de natureza qualitativa utilizamos o estudo de caso com metodologia fundamentada em André (2005), onde a observação participante e as entrevistas aprofundadas são, assim, os meios mais eficazes para que o pesquisador se aproxime dos sistemas de representação, classificação e organização do universo estudado.

\section{A Avaliação da Aprendizagem no curso de Letras da UVA}


A formação no Curso de Letras da UVA, que oferece as habilitações de Língua Portuguesa e Inglesa vem vivenciando historicamente desde a sua criação, em que foi proposto pela Diocese de Sobral, com o objetivo de subsidiar a melhoria da qualidade do ensino na Zona Norte cearense. Do docente que será formado pelo Curso de Letras da UVA espera-se a competência de saber lidar com diferenças, motivar os estudantes, promover um ambiente de troca de saberes e dar progressões ao processo de ensino e aprendizagem.

Em face das exigências formativas dos profissionais da área de Letras, o Curso que foi criado em Sobral-CE, nos idos de 1961, teve uma matriz curricular que passou por três reformas importantes sendo que em 1995 sofre a sua maior alteração. Em 2011, começou a ser gestada sua atual reforma, com reflexões significativas do corpo docente e da representação discente da IES.

As discussões, de acordo com o expressado em seu mais recente Projeto Político-Pedagógico, giravam em torno da construção de um ensino de qualidade, com forte formação intelectual dos seus formandos e com conhecimentos específicos sobre o ensino e a docência.

Neste sentido, a avaliação de aprendizagem é concebida como parte integrante do processo de formação dos discentes do Curso de Letras, com a possibilidade de diagnosticar questões relevantes da aprendizagem. Vale ressaltar que os princípios, os procedimentos e os instrumentos da avaliação de aprendizagem estarão adequados ao que apregoa as regulamentações da UVA sobre este aspecto e o que preceitua a atual LDB (Lei n 9394/96), em face da educação superior e da aferição do rendimento acadêmico.

Precisamos destacar que o Curso de Letras da UVA vem evoluindo historicamente sobre os procedimentos avaliativos graças aos esforços das legislações educacionais brasileiras, das discussões dos seus docentes e do movimento embrionário dos discentes, que questionam em sala de aula a avaliação utilizada, seus objetivos e seus fins educativos e pedagógicos.

Em se tratando da evolução avaliativa do Curso de Graduação da UVA acima mencionado podemos perceber que o mesmo encontrou em sua ampla trajetória histórica, em que são vislumbrados, mais de cinquenta anos de existência institucional, muitas polêmicas, contradições e impasses, mas que não cedeu ao comodismo nem muito menos de forma inerte a mudança do cenário nacional, uma vez que sempre se colocou na condição de protagonista de sua atuação. 


\section{Múltiplos olhares dos docentes e discentes sobre avaliação da aprendizagem}

Com elevado espírito investigativo, conseguimos um total de 31 depoimentos, entre discentes e docentes, que serão abaixo analisados:

\section{Depoimento dos discentes}

Foram coletados (23) depoimentos dos discentes em questionário aberto que continha tão somente a pergunta: “O que você entende por avaliação?” Os depoentes foram discentes dos diversos períodos do Curso, do segundo ao nono período, das habilitações em Língua Portuguesa e Língua Inglesa, sendo que o quinto período apresentou a maior predominância com 12 estudantes. Os mesmos eram na sua maioria do turno noturno, do sexo feminino, com faixa etária entre 18 e 25 anos. Residentes em Sobral-CE, A coleta era precedida de uma rápida abordagem aleatória junto ao discente do Curso de Letras e da explicação do objetivo da pesquisa, de forma muito natural e solidária. O sigilo da informação será aqui garantido através da nomenclatura Discente 1, 2, 3 e assim sucessivamente.

Para facilitar a apresentação das respostas obtidas e de sua compreensão foram agrupadas em 4 tabelas as respostas similares:

Tabela 1: Avaliação e sua natureza metódica

\begin{tabular}{|l|l|l|}
\hline DEPOENTE & TEXTO PROFERIDO & ENFASE PERCEBIDA \\
\hline Discente 1 & $\begin{array}{l}\text { "Avaliação é o método pelo qual o } \\
\text { professor realiza na sala de aula } \\
\text { como forma de identificar e analisar } \\
\text { os conhecimentos dos seus } \\
\text { estudantes diante dos temas } \\
\text { trabalhados e estudados na sua } \\
\text { disciplina". }\end{array}$ & $\begin{array}{l}\text { Rigor metodológico da avaliação na } \\
\text { sala de aula. }\end{array}$ \\
\hline Discente 2 & $\begin{array}{l}\text { "É um método na qual o professor } \\
\text { faz uso para verificar se o aluno está } \\
\text { com o rendimento bom, regular ou } \\
\text { mal em determinada disciplina". }\end{array}$ & $\begin{array}{l}\text { Verificação do rendimento da } \\
\text { aprendizagem. }\end{array}$ \\
\hline Discente 7 & $\begin{array}{l}\text { "É um tipo de método usado para } \\
\text { saber o nível intelectual de cada } \\
\text { aluno em determinada área e em } \\
\text { determinado momento". }\end{array}$ & $\begin{array}{l}\text { Verificação do rendimento da } \\
\text { aprendizagem. }\end{array}$ \\
\hline Discente 20 & $\begin{array}{l}\text { "Método que testa o conhecimento } \\
\text { do aluno, valendo assim } \\
\text { determinada pontuação que pode } \\
\text { levar o aluno a ser aprovado ou } \\
\text { reprovado". }\end{array}$ & $\begin{array}{l}\text { Verificação do rendimento da } \\
\text { aprendizagem. }\end{array}$ \\
\hline
\end{tabular}




\begin{tabular}{|l|l|l|}
\hline Discente 21 & $\begin{array}{l}\text { "Método pelo qual o professor } \\
\text { consegue entender o grau de } \\
\text { aprendizagem dos estudantes } \\
\text { orientando-os nas suas dificuldades } \\
\text { e compartilhando em seu } \\
\text { crescimento". }\end{array}$ & $\begin{array}{l}\text { Rigor metodológico da avaliação na } \\
\text { sala de aula. }\end{array}$ \\
\end{tabular}

Fonte: Formulário de depoimento sobre avaliação da aprendizagem - elaborado pelas autoras

Observamos que na tabela 1 , depoentes foram apresentados, sendo que dois disseram que a avaliação busca desenvolver um rigor metodológico em sala de aula e três enfocaram sua interface com o rendimento da aprendizagem.

Nesta tabela encontramos a assertiva de Freire (1996) ao enfocar a importância do rigor metodológico na prática docente como forma de influenciar um fazer metodológico crítico e reflexivo. Em se tratando da associação com o rendimento da aprendizagem, compreendemos que este aspecto está ligado com a estruturação do sistema, que exige a nota para os procedimentos de aprovação e reprovação. No entanto, muitos educadores esquecem-se da proposta mais inovadora traçada pela LDB (Lei $\mathrm{N}^{\circ}$ 9394/96) que coloca a avaliação muito mais processual e qualitativa.

Tabela 2: Avaliação e sua natureza processual

\begin{tabular}{|c|c|c|}
\hline DEPOENTE & TEXTO PROFERIDO & ÊNFASE PERCEBIDA \\
\hline Discente 3 & $\begin{array}{l}\text { "Processo pelo qual o aluno é } \\
\text { submetido ao final de cada } \\
\text { conteúdo dado, a mostrar o que } \\
\text { aprendeu". }\end{array}$ & Garantir a aprendizagem. \\
\hline Discente 5 & $\begin{array}{l}\text { "É um processo necessário no } \\
\text { desenvolvimento do ensino- } \\
\text { aprendizagem, porém não deve ser } \\
\text { concebido de forma arbitrária e } \\
\text { obsoleta, não deve julgar, nem } \\
\text { classificar, mas diagnosticar até que } \\
\text { ponto o aluno aprendeu". }\end{array}$ & Promover a avaliação diagnóstica. \\
\hline Discente 10 & $\begin{array}{l}\text { "É um processo que tem por } \\
\text { objetivo analisar os conhecimentos } \\
\text { adquiridos ou experiências } \\
\text { adquiridas". }\end{array}$ & Promover a avaliação diagnóstica. \\
\hline Discente 12 & $\begin{array}{l}\text { "É um processo pelo qual o } \\
\text { professor pode descobrir o } \\
\text { desempenho de seus estudantes, } \\
\text { saber se eles realmente estão } \\
\text { aprendendo o conteúdo repassado } \\
\text { em sala de aula e suas possíveis } \\
\text { dificuldades quanto a } \\
\text { aprendizagem". }\end{array}$ & Promover a avaliação diagnóstica. \\
\hline Discente 13 & $\begin{array}{l}\text { "É o processo no qual os estudantes } \\
\text { tem a oportunidade de demonstrar } \\
\text { os conhecimentos adquiridos } \\
\text { durante as aulas, como também o }\end{array}$ & Promover a avaliação diagnóstica. \\
\hline
\end{tabular}




\begin{tabular}{|l|l|l|}
\hline & $\begin{array}{l}\text { momento em que professor } \\
\text { classifica seus estudantes". } \\
\text { "É o processo que visa descobrir o } \\
\text { grau de aprendizagem de um } \\
\text { determinado conteúdo". }\end{array}$ & Promover a avaliação diagnóstica. \\
\hline Discente 14 & $\begin{array}{l}\text { "É o processo pelo qual se obtém, } \\
\text { através de observação, testes ou } \\
\text { conversações, o desempenho de um } \\
\text { indivíduo em determinadas } \\
\text { atividades". }\end{array}$ & Promover a avaliação diagnóstica. \\
\hline Discente 15 16 & $\begin{array}{l}\text { "É o processo que o professor se } \\
\text { baseia para dar ao aluno alguma } \\
\text { nota". }\end{array}$ & Promover a avaliação diagnóstica. \\
\hline
\end{tabular}

Fonte: Formulário de depoimento sobre avaliação da aprendizagem - elaborado pelas autoras

Na tabela 2, intitulada, foram apresentados os relatos de oito educandos, sendo que seis enfocaram o caráter diagnóstico da avaliação enquanto ação docente processual, um abordou a garantia da aprendizagem e outro mencionou a promoção da avaliação classificatória. Podemos verificar que a avaliação, segundo Hadji (2001) possui a função de realizar um diagnóstico processual dos estudantes em sala de aula, ou seja, avaliação na perspectiva formativa, facilitando o planejamento dos docentes. Esta relação processual deverá evitar dificuldades de aprendizagem e ampliar as consequências e habilidades dos docentes. Ao ser vista como garantia de promoção da aprendizagem a avaliação deve ser um ato interativo entre professores e estudantes que identificam objetivos comuns e trabalham para alcançá-los coletivamente.

Tabela 3: Avaliação e sua natureza instrumental

\begin{tabular}{|l|l|l|}
\hline DEPOENTE & TEXTO PROFERIDO & ENFASE PERCEBIDA \\
\hline Discente 6 & $\begin{array}{l}\text { "É apenas um instrumento que } \\
\text { utilizamos para verificar se o } \\
\text { aluno adquiriu os conhecimentos } \\
\text { básicos, relativos a um } \\
\text { determinado nível e se ele se torna } \\
\text { capaz de utilizar estes } \\
\text { conhecimentos em situações do } \\
\text { cotidiano". }\end{array}$ & \\
\hline Discente 19 & $\begin{array}{l}\text { "É um instrumento utilizado pelo } \\
\text { docente para medir e avaliar os }\end{array}$ & Instrumento Processual avaliativo. \\
& $\begin{array}{l}\text { conhecimentos adquiridos por } \\
\text { seus estudantes ao longo da } \\
\text { disciplina". }\end{array}$ & \\
\hline
\end{tabular}

Fonte: Formulário de depoimento sobre avaliação da aprendizagem - elaborado pelas autoras

Na tabela 3, apenas dois depoentes se manifestaram sobre este caráter da avaliação, sendo que um percebeu sua dimensão meramente instrumentalista e o outro a 
visualizou como um instrumental processo de busca de informações sobre a aprendizagem dos estudantes.

Segundo Hadji (2001), é inegável a natureza instrumentalizadora da avaliação para os docentes, que esperam através de seus resultados, compreender melhor os caminhos de seu fazer pedagógico e melhor atuar diante das dificuldades surgidas.

Tabela 4: Finalidades educacionais da avaliação

\begin{tabular}{|c|c|c|}
\hline DEPOENTE & TEXTO PROFERIDO & ÊEFASE PERCEBIDA \\
\hline Discente 4 & $\begin{array}{l}\text { "É a maneira mais viável de } \\
\text { obter informações importantes } \\
\text { não somente sobre o desempenho } \\
\text { dos estudantes, mas também } \\
\text { sobre os materiais e métodos de } \\
\text { ensino". }\end{array}$ & Promover a avaliação diagnóstica. \\
\hline Discente 8 & $\begin{array}{l}\text { "É perceber se o aluno alcançou } \\
\text { um determinado objetivo } \\
\text { proposto pelo professor". }\end{array}$ & Promover a avaliação diagnóstica. \\
\hline Discente 9 & $\begin{array}{l}\text { "É a maneira de observar na } \\
\text { prática, a teoria aprendida pelo } \\
\text { discente, refletindo seus pontos } \\
\text { fortes ou fracos para melhorar ou } \\
\text { ajudar no que ele necessita". }\end{array}$ & Promover a avaliação diagnóstica. \\
\hline Discente 11 & $\begin{array}{l}\text { "É uma forma contínua de medir } \\
\text { a assimilação do aluno a respeito } \\
\text { do conteúdo apresentado. Essa } \\
\text { forma aborda várias técnicas ou } \\
\text { uma só que cabe ao professor } \\
\text { definir". }\end{array}$ & Promover a avaliação diagnóstica. \\
\hline Discente 17 & $\begin{array}{l}\text { "É uma forma de analisar o } \\
\text { aprendizado, revendo conteúdos } \\
\text { aprendidos, buscando demarcar o } \\
\text { que realmente ficou". }\end{array}$ & Promover a avaliação diagnóstica. \\
\hline Discente 18 & $\begin{array}{l}\text { "Modo pelo qual o professor se } \\
\text { vale para questionar o educando } \\
\text { sobre o que aprendeu no decorrer } \\
\text { da disciplina". }\end{array}$ & Promover a avaliação diagnóstica. \\
\hline Discente 22 & $\begin{array}{l}\text { "É um diagnóstico que tem como } \\
\text { objetivo constatar e medir o nível } \\
\text { de conhecimento atingido pelo } \\
\text { aluno que está sendo avaliado". }\end{array}$ & Promover a avaliação diagnóstica. \\
\hline Discente 23 & $\begin{array}{l}\text { "É uma análise do conteúdo } \\
\text { assimilado pelo aluno, } \\
\text { geralmente atribuindo-se uma } \\
\text { nota". }\end{array}$ & Promover a avaliação diagnóstica. \\
\hline
\end{tabular}

Fonte: Formulário de depoimento sobre avaliação da aprendizagem - elaborado pelas autoras

$\mathrm{Na}$ tabela 4, foram apresentados oito depoimentos, sendo que seis enfocaram a função diagnóstica da avaliação, um deu ênfase a sua função formativa e um mencionou sua importância na percepção do rendimento da aprendizagem. Tal tabela corrobora as informações obtidas nos depoimentos anteriores e nos fazem verificar que os discentes 
do Curso de Letras da UVA têm uma percepção muito clara da função diagnóstica da avaliação no processo de ensino-aprendizagem, sentem também um pouco de necessidade da avaliação na sua função formativa e ainda acrescentam sua importância processual nos dados do rendimento da aprendizagem.

Para Libâneo (2001), muitos problemas educacionais poderiam ser evitados se os docentes usarem com critérios bem definidos, a avaliação na sua dimensão diagnóstica. Os discentes, por sua vez, sentem tal necessidade, de um acompanhamento mais direcionado de suas aprendizagens iniciais e finais, exigidas pela escola e pela comunidade escolar.

\section{Depoimento dos docentes}

Vejamos agora as respostas atribuídas pelos docentes do Curso de Letras da UVA que responderam a mesma questão acima analisada, desta feita acrescentando se era possível formar estudantes competentes sem uma prática de ensino rigorosa e distante de uma abordagem puramente classificatória.

Os depoimentos dos 08 docentes participantes envolveram as duas habilitações do Curso, sendo que houve maior predominância os docentes de Língua Portuguesa. Os docentes do Curso já mencionado são jovens, estão numa faixa etária de 25 a 35 anos, possuem em média o mestrado, são na sua maioria do sexo masculino e trabalham na UVA cerca de pelo menos cinco anos, com vínculo empregatício efetivo, substituto ou contratado pelo seu Instituto de Ensino.

Seus relatos, realizados individualmente, foram velados pela experiência e pelo compromisso com os docentes, revelando que tipos de profissionais estão querendo formar e como estão trabalhando na organização de ensino para garantir resultados promissores de aprendizagem.

Optamos por apresentar os relatos dos professores do Curso com a sua respectiva análise logo em seguida, obtemos a participação de 08 docentes, sendo que o Curso possui 20 professores. Em face do questionamento: O que você entende por avaliação? E seus possíveis desdobramentos reflexivos, os docentes assim se manifestaram em seus depoimentos: Docente 1: “É possível formar estudantes sem uma prática avaliativa rigorosa, desde que se dê ao aluno a possibilidade de ele saber que 
"este" ou "aquele" curso ou disciplina é para ser vivido 24 horas. O tempo o formará como um bom ou mal profissional."

Porque no lugar de rigorosa ela deveria ser vigorosa, diagnosticando as dificuldades com o objetivo de fortalecer a aprendizagem na retomada de esforços que levasse os estudantes aprenderem de verdade. Não haveria necessidade de classificação, não precisava separar aptos e não aptos, se apoiando num único instrumento de avaliação a nota. Era preciso que a avaliação fosse grupal, e os resultados uma avaliação resultante do esforço conjunto dos estudantes que em equipe se estimulam e se ajudam. (DOCENTE 2)

Nestes dois depoimentos percebemos que os docentes desejam uma avaliação formativa, geradora de melhores resultados do processo de ensino-aprendizagem. Entendem a função classificatória da avaliação e seus enfoques reducionistas da própria avaliação.

Os docentes entendem que a avaliação não deve ter uma finalidade somativa, mas ser alvo de inúmeras interpretações e que a mesma, embora envolvida num amplo rigor metódico, pode apresentar falhas. Usada desde os primórdios das escolas brasileiras, a avaliação da aprendizagem vem sendo revistada pelos docentes que tentam torná-la mais eficaz, inclusive na sua dimensão educacional mais ampla. Sobre esta ideia os relatos afirmam: Docente 3: "Dependendo da metodologia aplicada em sala de aula, o professor poderá obter resultados satisfatórios na formação do aluno, sem precisar adotar uma prática avaliativa rigorosa e classificatória."

Logo, como assinala o Docente 4 quando declara que : "Mas vale salientar que toda avaliação está possível de falhas." Os docentes entendem que a avaliação não deve ter uma finalidade somativa, mas ser alvo de inúmeras interpretações e que a mesma, embora envolvida

num amplo rigor metódico, pode apresentar falhas. Usada desde os primórdios das escolas brasileiras, a avaliação da aprendizagem vem sendo revistada pelos docentes que tentam torná-la mais eficaz, inclusive na sua dimensão educacional mais ampla.

Os docentes possuem uma atitude muito otimista diante dos resultados da avaliação, em face de suas finalidades, transformações educativas e sociais. Sobre estas reflexões recorre-se aqui aos depoimentos: Docente 5: “Acredito que não. Principalmente se levarmos em conta que existem certas medidas de avaliação e de ensino "paternalistas" que dificultam o processo satisfatório de ensino-aprendizagem do aluno." Docente 6: "Todo processo avaliativo deve ser rigoroso, seja classificatório, ou 
não. Formar estudantes competentes é necessário é possível. Isto vai além dos processos avaliativos".

Assim, o passado, com seus acertos e erros, deve ser analisado no presente como fonte inspirada de mudanças, porque a esperança deve ser a atitude permanente dos educadores e dos educandos nas instituições de ensino do nosso país.

Nos depoimentos 7 e 8 os docentes manifestaram sua preocupação com os resultados partilhados na avaliação da aprendizagem. Há uma compreensão de responsabilidade mútua, que não afasta o rigor metodológico. No entanto, esse mesmo rigor poderá ser amenizado por posturas mais quantitativas de interpretação dos resultados da avaliação que devem produzir essencialmente o crescimento humano dos atores do processo de ensino e de aprendizagem. Sobre este exposto os docentes declararam que: "Para aprender é preciso ter responsabilidade e interesse e nem sempre é necessário que para isso sejamos rigorosos". (DOCENTE 7). "Aprender é uma atitude de crescimento humano". (DOCENTE 8).

\section{Considerações finais}

Com base na discussão necessária sobre a avaliação da aprendizagem e suas implicações no ato pedagógico dos docentes e discentes, tendo como foco de análise o Curso de Letras da UVA, por sua importância na formação de educadores para a Zona Norte do Estado do Ceará, nas Habilitações em Língua Portuguesa e Língua Inglesa. O referido Curso vem sofrendo a implantação de uma reformulação curricular, que pretende aperfeiçoar o processo formativo desses futuros educadores.

Nesse sentido, em face do estudo teórico-prático aqui registrado, descobrimos que 1) a avaliação ainda é um tema cercado de mitos e impasses, que apresenta desafios conceituais, procedimentais e atitudinais; 2) a avaliação possui finalidades, funções, tipos e instrumentos avaliativos que poderão facilitar a vida dos docentes e dos estudantes, se forem reconhecidos e utilizados corretamente pelos mesmos em sala de aula; 3) aplicar uma avaliação em sala de aula é um caminho de mão dupla, pois produzirá resultados para os docentes e discentes, exigindo uma análise processual das situações que levaram a tais resultados; 4) os docentes do Curso de letras da UVA estão tentando realizar uma avaliação de aprendizagem mais inovadora, proposta inclusive pelo seu Projeto Político-Pedagógico, no entanto, reconhecem os problemas históricos 
da avaliação e lutam para vencer seus mitos formativos; 5) os discentes do Curso de Letras da UVA têm uma visão muito clara da avaliação da aprendizagem na sua dimensão diagnóstica e formativa, mas criticaram as posturas classificatórias que alguns docentes teimam em manter, por serem reducionistas do ato avaliativo. 6) a perspectiva da avaliação emancipatória ainda é embrionária, porém é reconhecida como necessária e viável nos Cursos de graduação, de forma especial, nas licenciaturas, por seu caráter de formação consciente e crítica dos profissionais de educação. 7) os aspectos legais da avaliação não são ineficientes na prática pedagógica, mas precisam de uma maior análise por parte dos docentes e de um maior reconhecimento por parte dos discentes; 8) avaliar não é um ato isolado ou individual, mas uma decisão influente no fazer pedagógico e determinante de suas transformações;

Por todas as reflexões acima apresentadas consideramos que o ato de avaliar é complexo e polêmico, com desdobramentos psicológicos, pedagógicos, sociais e políticos, capazes de conduzir à conservação ou à transformação da própria sociedade e de seus indivíduos. O tema aqui abordado é inesgotável e poderá ser desvelado e o futuro pertence aos que detiverem melhores ferramentas de aprendizagem e de inserção social. Assim avaliar é preciso, caminhar é caminhar é necessário e mudar é fundamental, porque somos educadores e educandos, num ato permanente de aprendizagem, de ensino e de humanização.

\section{REFERÊNCIAS}

ANDRÉ, M. E. D. A. Estudo de caso em pesquisa a avaliação educacional. Brasília: Líber Livro editora, 2005.

ANTUNES, C. Como desenvolver as competências em sala de aula. 4. Ed.

Petrópolis:

Vozes, 2001.

BARRETO, A. C. de O. et al. Método de avaliação discente em um curso de graduação baseado em metodologias ativas. In: Revista Ibero-Americana de Estudos em Educação, Araraquara, v, 12, n. 2, p. 1005-1019, 2017. ISSN: 1982-5587. Disponível em: <http://dx.doi.org/10.21723/riaee.v12.n2.8745>. Acesso em: 10 mar. 2017.

BATISTA, S. M. M.; DE MELO IBIAPINA, I. M. L. Possibilidades da prática avaliativa no ensino superior: uma experiência colaborativa. Revista Ibero-Americana de Estudos em Educação, v. 11, n. 4, p. 1994-2011, 2016. E-ISSN 1982-5587. 
Disponível em: <http://dx.doi.org/10.21723/riaee.v11.n4.7392>. Acesso em: 10 mar. 2017.

BRASIL. Lei n. 9.394, de 20 de dezembro 1996. Estabelece as Diretrizes e Bases da Educação Nacional. Diário Oficial da União, Brasília, DF, 23 dez. 1996. p. 27894.

BRASIL. Secretaria de Educação Fundamental. Parâmetros curriculares nacionais: introdução aos parâmetros curriculares nacionais. Brasília: MEC/SEF, 1998.

CARNEIRO, M. A. LDB Fácil: Leitura crítico-compreensiva: artigo a artigo. 9.ed. Petrópolis, RJ: Vozes, 1998.

FREIRE, P. Educação como Prática da Liberdade. 14. Ed. Rio de Janeiro: Paz e Terra, 1983.

FREIRE, P. Pedagogia da Autonomia: saberes necessários à prática em construção da pré-escola à universidade. 9. Ed. Porto Alegre: Mediação, 1996.

GARCIA, R. L. A avaliação e suas implicações no fracasso/sucesso. In: ESTEBAN, M. T. (Org.). Avaliação: uma prática em busca de novos sentidos. 5. Ed., Petrópolis: DP et Alii, p. 25-42, 2008.

HADJI, C. Compreender que a avaliação formativa não passa de uma "utopia promissora". In: HADJI, CHARLES. Avaliação desmistificada. Porto Alegre: Artmed, 2001.

HOFFMANN, J. Avaliação mediadora. 31. ed. Porto Alegre: Editora Mediação, 2011.

LIBÂNEO, J. C. Didática. 15.ed. São Paulo: Cortez, 1994.

LIBÂNEO, J. C. Organização e gestão da escola: teoria e prática. Goiânia: Alternativa, 2001.

LUCKESI. C. C. Avaliação da aprendizagem escolar. 9. Ed. São Paulo: Cortez, 1999.

MAGALHÃES, G. M.; MARSIGLIA, A. C. G. A avaliação na perspectiva da Pedagogia Histórico-Crítica. In: Revista on line de Política e Gestão Educacional, Araraquara, n.15, p.235-248, 2013. ISSN: 1519-9029. Disponível em: <http://seer.fclar.unesp.br/rpge/article/view/9354/6206>. Acesso em: 10 mar. 2017.

PERRENOUD, P. Avaliação: da excelência à regulação das aprendizagens. Porto Alegre: Artmed, 1999.

PROJETO POLİTICO-PEDAGÒGICO DO CURSO DE LETRAS DA UVA - Versão 2011, cedido pela Coordenação do Curso de Letras da UVA.

SAVIANNI. D. Saber escolar, currículo e didática. 3. Ed. Campinas: Autores Associados, 1998.

SAVIANNI. D. Democratização da escola pública. São Paulo: ática, 1967. 
VIEIRA, J. J.; MORAES, M. P. de.; VIEIRA, A. L. da C. Avaliação e Políticas Públicas em Educação: fatores determinantes na qualidade e formação de profissionais. $\mathrm{n}^{\mathbf{o}}$ 16, 2014. In: Revista on line de Política e Gestão Educacional, Araraquara/SP, n.16, p. 4-000, 19, 2014. ISSN: 1519-9029. Disponível em: < http://seer.fclar.unesp.br/rpge/article/view/9357/6208 >. Acesso em: 10 mar. 2017.

\section{Como referenciar este artigo}

FELIX, Neudiane Moreira.; MARTINS, Evaneide Dourado. Avaliação do ensinoaprendizagem na percepção de discentes e docentes no curso de Letras da Universidade Estadual Vale do Acaraú. Revista on line de Política e Gestão Educacional, Araraquara, v.21, n.2, p. 502-521, maio-ago. 2017. Disponível em: <http://dx.doi.org/10.22633/rpge.v21.n.2.2017.9976>. ISSN: 1519-9029.

Submetido em: 01/06/2017

Aprovado em: 10/07/2017 